First published in Evans, K. and Waite, E. (2010) Stimulating the innovation potential of 'routine' workers through workplace learning, Transfer: European Review of Labour and Research, Volume 16, Number 2, ISSN 1024-2589, pp243 - 258.

\title{
Stimulating the innovation potential of 'routine' workers through workplace learning
}

\author{
Karen Evans and Edmund Waite \\ Institute of Education, University of London
}

\section{Summary}

Governments worldwide seek to upgrade the 'basic skills' of employees deemed to have low literacy and numeracy, in order to enable their greater productivity and participation in workplace practices. A longitudinal investigation of such interventions in the United Kingdom has examined the effects on employees and on organisations of engaging in basic skills programmes offered in and through the workplace.

'Tracking' of employees in selected organisational contexts has highlighted ways in which interplay between formal and informal workplace learning can help to create the environments for employees in lower grade jobs to use and expand their skills. This workplace learning is a precondition, a stimulus and an essential ingredient for participation in employee-driven innovation, as workers engage with others to vary, and eventually to change, work practices.

\section{Résumé}

\section{Zusammenfassung}

\section{Keywords}

Adult learning, skills utilisation, work environments, formal-informal learning , employee development, innovative practice, workplace learning, literacy, routine work

[Corresponding author: Professor Karen Evans, Institute of Education, University of London, 20, Bedford Way, London WC1H OAL.

k.evans@ioe.ac.uk

\section{Introduction}

With the currently fashionable focus on highly paid 'knowledge workers' as drivers of change and competitive renewal, employees at the lower end of the earnings distribution are often left out of consideration in organisations' plans for workforce development. Yet employee-driven innovation crucially rests on involvement of the whole workforce.

Qualification and skill levels are highly correlated with employment status; within employment, training beyond minimum job requirements is most likely to be given to those who are in relatively high status and high-paid jobs (Sargant et al., 2000), Ananiadou et al., 2003) This may appear rational from an employer's point of view, since those with higher education levels and higher literacy and numeracy skills are also assumed to benefit faster from training, and so cost less to train. But this 
compounds, rather than alleviates, the relative skill disadvantage of those who enter the workforce with low skills, and means that employer-financed training has tended to do rather little to raise the absolute skill level of those at the lower end of the earnings distribution. This has provided part of the case for publicly funded government interventions in this area, and governments worldwide do seek to upgrade the 'basic skills' of employees deemed to have low literacy and numeracy, with the aim of enabling their greater productivity and participation in workplace practices. In this article we begin with unique evidence from a longitudinal investigation of such interventions in the UK, arguing that an emphasis on skills deficits often fails to take account of employees' capacities to use their existing skills and competencies and tailor them to the actual demands of the workplace. Through evidence from organisational case studies, the analysis is extended into ways in which formal and informal workplace learning can connect in creating environments and stimuli for employees in lower grade jobs to engage with their work in new ways. This workplace learning is a precondition and an essential ingredient of participation in employee-driven innovation, as workers engage with others to vary, and eventually to change, work practices.

Since the launch of a national strategy to 'upgrade' basic skills in 2001, the UK government has invested heavily in the development of literacy, numeracy and ESOL (English for speakers of other languages) amongst adults in England, with parallel developments in Scotland, Wales and Northern Ireland. This strategy has entailed the allocation of over £5bn towards ring-fenced funding for free literacy, numeracy and ESOL provision; the development of core curricula, learning, materials and national qualifications based on new standards; new qualifications for initial teacher training and professional development for teachers and the setting of challenging national targets for the achievement of qualifications. As part of this overall strategy, the UK has invested in the funding of literacy, numeracy and ESOL provision at work. Offered through face-to face tuition or online learning in the workplace, this has taken the form of discrete courses or 'embedded' skills development in vocational, job-specific and information technology training. The Leitch Review of Skills (2006) and the subsequent 'Train to Gain' national initiative have further underlined the importance of literacy and numeracy provision in the workplace and set challenging new targets for improving the attainment of literacy and numeracy skills by 2020 .

The drive to improve skills that are seen as the prerequisites for work (hence 'basic') stems from a perceived 'skills crisis' amongst the UK population. The findings of the OECD-conducted International Adult Literacy survey (IALS), which claimed that seven million adults (one in five of the UK population) had poor literacy and numeracy skills (at or below the age of an 11-year-old child) provided an important justification and catalyst for the establishment of the UK's national strategy. 'The regular employment of such statistics implicitly assumes an 'autonomous' (Street, 1993) model of skills in which literacy and numeracy are treated as a discrete set of technical skills that individuals either possess or lack and which exists independently from context. Such an approach contrasts with a burgeoning research tradition in the UK - which views literacy in terms of 'social practices' (e.g. Street, 1993; Barton, 1994; Barton and Hamilton, 1998; Gee, 1996; Papen, 2005), highlighting the widely variant use of literacy practices in differing social and institutional contexts and the key role of power relations in shaping and validating such practices. 


\section{Concepts and perspectives: skills, workplace learning and innovation}

In their review of contemporary Nordic research on workplace learning, Elkjaer et al. espouse the importance of taking account of the wider policy context and power relations in both shaping, selecting and legitimizing differing versions of workplace learning: 'This would imply a research agenda that not only focuses on the relations between individuals and workplaces but also opens out towards analysing how economic and political agendas and discourses co-constitute individuals, workplaces and the learning that can/cannot or does/does not take place in these key sites of social action' (Elkjaer et al., 2007: 37). In this context, different perspectives on skills generate much controversy about what skills are and how they should be measured.

Theoretical perspectives on skill differ according to where skill is considered to reside. Some perspectives, principally rooted in psychology and economics, view skills as attributes of the person. By contrast, management and industrial relations specialists, together with occupational psychologists, see skills as residing in the job. Sociologists, anthropologists and social historians see skills as socially constructed and residing in settings, with a focus on how skills are shaped by social relations.

Approaches that view skills as individual attributes are often associated with human capital theories, which argue that in market economies a person's value as an employee is determined by their knowledge and abilities, and the extent to which their knowledge and abilities are in supply and demand in the labour market give them value as 'skills'. One of the problems with these approaches is the validity of the definitions and measures of skills that are used, since context determines the value of the skill. In versions that focus on the job, skill is seen as an objective feature of work; it is defined by the requirements of the job and can be measured through an analysis of job content. Levels of skill are often differentiated according to the complexity of the job and according to the discretion that the post-holder has in making decisions and judgments. While levels of education, training and experience are also associated with the skills level of jobs, there are often disparities between the skills people possess and those they are expected to use at work.

Approaches that focus on 'skill in the job' and 'skill in the individual' are often criticised for ignoring the social and historical development of the different conceptions of skill. Skill is a powerful concept since it implies a measure of the worth. The skills that are recognised and rewarded reflect the power and influence of social groupings. They are used by different interest groups to claim status, preferential treatment and higher rewards, for example, in the valuing of cognitive skills over the practical and vocational and in the rewarding of skills according to gender.

The tacit dimensions of skill are increasingly important, as social skills, organisational skills and abilities to deal with unfamiliar situations are emphasised in job requirements. The growing interest in their codification stems from recognition that these tacit skills are very important in the performance of individuals, organisations, networks and possibly whole communities. 'Know-how', which includes a range of situated literacy, involves complex linkages between skill formation and personal knowledge developed through experience. This is so often taken for granted that the extent to which it pervades our activities is unappreciated. 
Drawing on the findings of the 'Adult Basic Skills and Workplace Learning' project (a longitudinal, mixed methods study of the impact of 'Skills for Life' provision on employees and organizations in England) we argue that policy imperatives underpinning the Skills for Life national strategy, which have sought to highlight a 'skills crisis' based on narrowly circumscribed perceptions of literacy and numeracy, have led to insufficient recognition of the complex constitution of employee skills and competencies, their situated literacies and 'know-how' in differing organizational contexts as well as the significance of learning outside formal educational channels. In keeping with this approach, we define 'workplace learning' broadly in terms of learning that takes place in and through the workplace and derives its purpose from the context of employment (Evans et al., 2006: 9) rather than merely in terms of learning that takes place in formal provision in the workplace. The workplace learning purposes that are derived from the context of employment include the following categories, further elaborated in Evans et al. (2010):

- Socialisation and enculturation ('how we do it here');

- Competence, performance and standards (productivity, safety, licence to practice);

- Innovation (renewal and competitive advantage);

- Equity and social justice (unionisation and employee entitlement).

Most workplace learning is driven by one or more of these purposes. We argue, on the basis of research evidence, that the interplay between forms of learning that are formal (programmes of instruction) and informal (embedded in work customs, environments and practices) can encourage employee involvement in varying work practices and in working with others to improve them. At what point does varying practice for improvement go beyond continuous adaptation to become innovative? The process of innovation can itself be gradual, continuous and orderly. Even the simple process of incrementally adapting has innovative overtones if the ensuing practices eventually lack continuity with those previously used. In this way the dayto-day exercise of employees' situated literacies and workplace 'know-how' can yield forms of invention that often remain overlooked in typical accounts of product and process innovation.

In this context, and with these considerations in mind, we show how the large scale UK government intervention in support of 'lower-skilled' employees' engagement in workplace learning has played out in practice in the organisational dynamics of a range of private and public sector organisations.

\section{'Skills for Life' policy assumptions and the UK economy}

UK 'Skills for Life' national strategies are underpinned by assumptions about the negative impact of large-scale literacy and numeracy skills deficiencies on the UK economy. In particular, the increasing encroachment of the so-called 'knowledge economy' is frequently cited as an important justification for developing literacy and numeracy skills amongst lower-level employees (see DfEE, 2001: 9).

The employment of the phrase 'knowledge economy' in policy discourse on workforce development and lifelong learning in general tends to follow a process of 'nominalisation' (Fairclough, 2003: 44-45) whereby complex processes are depicted as a self-governing 'thing' or entity. The objectification of the 'knowledge economy' 
means that it is depicted as an inevitable feature of contemporary life. The precise impact of the 'knowledge economy' on literacy and numeracy practices amongst lower-level employees (the original target of the UK strategy for workplace 'basic skills') is never specified in policy documents. Instead policy statements tend to be based more on a 'logic of appearances' (Fairclough, 2003: 94-95) than on empirical evidence. Efforts to estimate the cost of poor literacy and numeracy skills on the UK economy have also been bedevilled by the same lack of robust evidence. 'Skills for Life' promotional literature has relied heavily on a consultancy report by Ernst and Young carried out in the early 1990s that estimated the 'cost to the country as a whole could be as high as $£ 10$ billion a year'. Aside from various methodological problems surrounding the original research on which these claims were based, such estimates are based on a line of reasoning which assumes that large-scale skills deficiencies (defined in 'autonomous' terms) are distributed with some consistency across the UK economy. This approach ignores the widely diverging uses of literacy and numeracy across different sectors and occupational strata as well as the significance of organizational contexts in shaping literacy and numeracy practices.

Analysis of the UK's 2006 Skills Survey suggests than an over-supply rather than deficit of skills may be evident in large swathes of the UK economy; there may be as many as 6.9 million jobs in the British economy that require no qualifications to obtain the post, but just 2.2 million adults with no qualifications (Felstead et al., 2007: 80). A growing literature has contested policy assumptions about the heightening of knowledge and skills demands in all sectors of the economy and has highlighted the persistence of large areas of the economy that continue to entail routine or menial work (e.g. Keep, 1999; Mayhew and Keep, 1999; Thompson, 2004). Such a literature has important potential ramifications in challenging some of the assumptions that underpin national strategies for upgrading 'basic skills'. If it is the case that employees in large areas of the UK (and other Western economies) are still engaged in relatively routine, menial work then this has important implications in potentially limiting the need for higher level literacy and numeracy skills in these occupations. Conversely, there is a suggestion that skills such as literacy are beginning to assume greater importance as a correlate of increased employee involvement in workplaces, while the physical, routine nature of tasks remains relatively unchanged (Green, 2009).

\section{Adult 'basic skills' and workplace learning: research overview}

In investigating the impact of government interventions in workplace learning, we have tracked both participating employees and their workplaces between 2004 and 2008, with selective follow-up from 2009. .i Five hundred and sixty seven employees and 53 workplaces were involved. We tested the reading and writing skills of participants at the start of their courses, and then a year, and two years later. We also gathered in-depth information on all three occasions about their jobs, learning experiences, education, attitudes to work and aspirations, acknowledging the complex interplay between the motivations and behaviour of active adult learners, the environment in which they learn, and the nature of their programme; and correspondingly looked at a variety of outcomes. At the same time, we interviewed managers and training managers, and course tutors. Sub-sets of 10 sites and 64 employees were studied and interviewed in greater depth, also with follow-up over a four-year period. Workplace basic skills courses have typically provided a standard, initial 30 hours of instruction in or near the actual work-site; have focused 
predominantly on literacy, are often built around the use of computers ('Laptops and literacy' is a typical title) and use teaching material that is generalist rather than directly related to occupations. The research has shown, in summary (see Wolf and Evans, 2009), that both participants and companies engaged in workplace literacy programmes are motivated by personal and organisational commitments that extend beyond immediate productivity enhancement. Adults who participate in workplace courses are somewhat more likely than their peers to continue with formal learning in later years. Those who actively use literacy in their day-to-day lives in the workplace and beyond it are the ones who will continue to improve. Workplace courses successfully reach adults who do not participate in other formal learning, but when delivered through 'outside' initiatives disconnected from core organisational concerns, they often fail to create any lasting infrastructure (Wolf and Evans, 2009 Evans et al., 2009; Evans and Waite, 2009; Wolf, Aspin, Waite and Ananiadou 2010).

\section{Employees' motivations for engagement in workplace programmes}

Quantitative and qualitative data from the 'Adult Basic Skills and Workplace Learning' project indicate that employees have diverse motivations for engagement in this type of workplace provision. The findings raise important questions in relation to the supposed prevalence of large-scale basic skills deficiencies.

Figure 1 provides data on the two most important outcomes that learners wanted or expected from their course from the first phase of structured interviews (conducted at the beginning of the course). This is then compared with the two most important outcomes that learners actually felt they achieved from the course, based on data from follow-up structured interviews (undertaken after the course had been completed).

Figure 1. 


\section{Most important expected and actual benefits from the course}

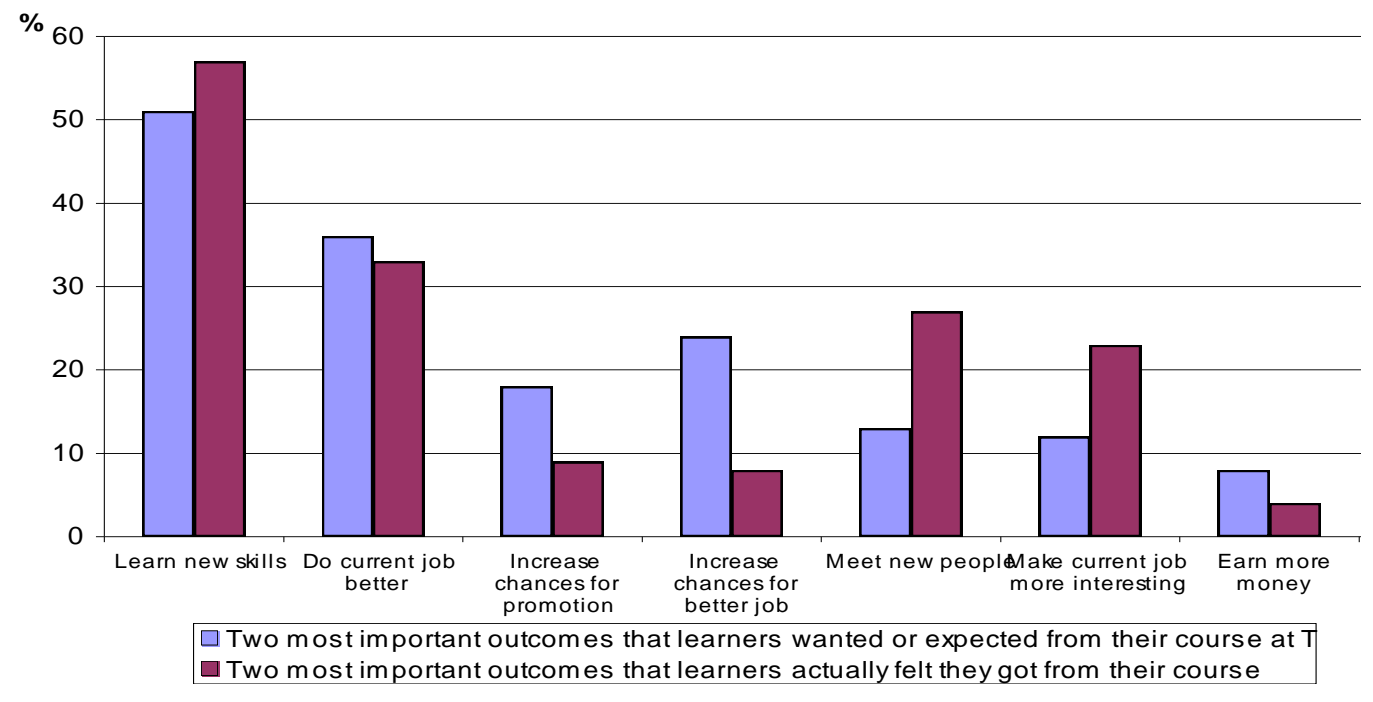

Figure 2 provides data on the perceived outcomes of the course on an item by item basis, revealing the significance of attitudinal outcomes and the development of generic new skills. Positive outcomes are experienced in increased confidence at work and in life outside work, greater willingness to engage in further learning, enhanced awareness and appreciation of the English language, increased motivation to pursue a range of hobbies, personal interests and commitments outside the workplace. In in-depth interviews, many employees linked low levels of confidence to previously negative educational experiences at school and elsewhere. As argued in other publications (e.g. Wolf and Waite, 2007), 'Skills for Life' workplace provision has been effective in attracting adults who have not successfully engaged with other forms of provision as a result of its accessibility, convenience and its relative distance from intimidating associations. While most adults do not have to improve their basic educational level in order to participate in innovation, our evidence shows that those with low literacy are often vulnerable when new work practices are introduced, particularly where these involve textualisation. So while these features of workplace courses do not in themselves lead to employee involvement in innovation, participation in these courses can potentially act as one of the preconditions for employee involvement in changing work practices as well as 
potentially providing a catalyst for further workplace learning.

\section{Outcomes of course (item by item basis)}

\begin{tabular}{ll}
\hline Increased confidence at work & $66 \%$ \\
\hline Developed new skills & $61 \%$ \\
\hline Increased confidence outside work & $59 \%$ \\
\hline Met new people & $58 \%$ \\
\hline Affected how current job is done & $45 \%$ \\
\hline Helped with use of computers outside work & $33 \%$ \\
\hline Helped with use of computers at work & $27 \%$ \\
\hline Made work more interesting & $25 \%$ \\
\hline Increased chances for promotion & $11 \%$ \\
\hline Increased chances of a better job & $10 \%$ \\
\hline Helped earn more money & $2 \%$ \\
\hline
\end{tabular}

* $40 \%$ elaborated: all reported positive impact

Whether or not a course increased confidence at work was highly (and positively) related to whether a learner also thought it had hel ped them to do their current job better/had affected how they did the job.

Figure 2. Participants' reported outcomes workplace programme participation

Personnel managers frequently explained their organizations' motivations for running these courses as rooted in the desire to boost staff morale, develop a positive company ethos and foster the personal development of employees. The need to strengthen the psychological contract between employer and employee provided a major impetus to the establishment of workplace courses and provided another precondition for innovation in workplaces (see also Evans et al., 2006).

\section{'Use it or lose it': the significance of employing literacy skills in the workplace}

The longitudinal dimension of the research has entailed literacy assessments at three intervals, allowing us to trace the longer-term impact of the courses on measured skills as well as the impact of shifting organizational structures on the uses of literacy and numeracy at work.

Those learners we interviewed in-depth who had made most literacy gains between the first and second literacy assessment (appearing in the first quartile of learners who had made most improvement between Time 1 and Time 2 literacy assessments) had generally continued to develop their skills in the workplace and beyond. For example, in the case of a weapons manufacturing company, the learner whose level of literacy had improved most substantially in that organization had been promoted after the course and now actively used a wider range of literacy skills as part of a broader organizational shift towards the delegation of responsibility to lower-level employees. Whereas during the Time 1 in-depth interview he attached little significance to the literacy component of the course, at the Time 2 in-depth interview he retrospectively valued his participation in the course in the light of his recent promotion. 
'I realise that it (the literacy component of the course) was quite an important part. Before I wasn't really writing too much, and now obviously I use it a lot more, do more handwriting as well as on the computer.'

Other learners we interviewed in this organization who had not benefited from these structural changes within the organization and had not been promoted and continued to engage in the same working routines (which entailed minimal use of literacy) made either no progress or negligible gains in their literacy scores. For example, Roger Taylor, who was doing the same type of job, continued to have minimal exposure to literacy practices and whose literacy score declined between Time 1 and Time 2 literary assessments reported the following: 'l've never been particularly good at the English side of things ... I feel like l'd like to improve it but I don't find it necessary in what I do. I don't do an awful lot of writing ...'

This underlines the fact that ultimately the development of such skills rests on their employment in practical work settings, a finding that is further substantiated in correlation between growth in literacy scores and 'job change' found in the wider sample, where 'job change' refers to taking on new responsibilities or additional tasks within an existing role as well as taking on a completely new role at work.

Figure 3. Relationship between growth in reading score (between first and second interview) and job change

\begin{tabular}{lrrrc} 
All cases & Coef. & Std. Err. & \multicolumn{1}{l}{$\mathrm{t}$} & $\mathrm{P}>\mathrm{t} \mid$ \\
\hline Time 2 reading score & -.38 & .05 & -6.98 & 0.000 \\
\hline Version A & & & & \\
\hline job change & -12.34 & 2.66 & -4.64 & 0.000 \\
\hline constant & $\mathbf{5 . 3 1}$ & $\mathbf{2 . 5 7}$ & $\mathbf{2 . 0 7}$ & $\mathbf{0 . 0 4 0}$ \\
\hline
\end{tabular}

Number of observations $=182, \mathrm{R}$-squared $=0.2292$

In our overall sample, employees have made modest literacy gains as a result of engaging in literacy courses. This finding is understandable in light of their relatively light exposure to employment of literacy and numeracy skills in the workplace. Those for whom English was not their first language ('ESOL') made larger, significant gains in their measured literacy. This too is consistent with the 'use it or lose it' principle, since these employees are on a rather different 'learning curve' from native English speakers. They experience challenge and opportunity in practising their developing English language skills in everyday activities in rather different ways.

\section{How is workplace learning related to working practices?}

In this section we turn our attention to the types of learning, formal and informal, that employees engage in at the lower end of the earnings distribution. How are workplace learning activities related to working practices? How can workplace 
learning stimulate or support employees in varying their working practices and finding new ways of carrying out work tasks and processes?

During the course of in-depth interviews with a sub-sample of 64 employees from 10 sites, the majority of learners self-reported that they coped adequately with their existing literacy and numeracy skills in the workplace. Approximately one-third mentioned that they struggled with aspects of literacy or numeracy in general (whether at work or home); with half of these (one-sixth of the sub-sample) revealing that poor literacy or numeracy skills had either adversely affected their work or prevented them from fulfilling career plans. These included three caretakers at a Local Authority who had encountered increasing use of report-writing in order to document instances of damage to property and two residential care-workers at an old people's home who had similarly encountered increasing documentation in the workplace (mainly in the form of 'care-plans' for the residents of the home). Tracy Beaumont, a 'quality assessor' at Coopers (a food manufacturing company) admitted to poor spelling but felt that poor literacy skills were only exposed on training days when she would dread the experience of being asked to read material out loud. Similar anxieties beset Bennie Thomas, a ticket machine operator at STS systems, who struggled severely with reading and writing (and admitted that this had curbed his opportunities for promotion) but managed on a day-to-day basis and only felt 'caught out' on training days. ESOL ${ }^{1}$ learners, for understandable reasons, tended to see a more direct link between participation in workplace learning and job-specific considerations but only two learners (an operative at 'Brightland Bakeries' and an admin officer at STS systems) reported that their existing levels of English adversely affected their current job responsibilities. Harry Jackson, an instructor at STS systems, felt that his career prospects had been impeded by severe dyslexia but had become adept at employing various 'avoidance strategies' in order to cope with his existing job.

Many learners accounted for their capacity to cope with their existing literacy and numeracy strategies on the basis of relatively light exposure to literacy in the workplace (e.g. bus drivers who only occasionally had to fill in an incident report form). In this respect it is important to take account of widely differing organizational contexts; whereas some jobs have been affected by such processes as increasing report-writing in response to auditing demands and increasing health and safety regulations as well as the 'levelling out' of management structures in some companies, there are also many jobs and organizational contexts which entail negligible use of literacy practices. Data from qualitative interviews suggest the introduction of new technologies (which is frequently cited in 'Skills for Life' literature as necessitating higher level literacy and numeracy skills) can often pre-empt or allow for the circumventing of the use of literacy and numeracy skills either by supervisors or by the employees themselves; as in the case of a worker at 'Coopers' (a food manufacturing company) who told us she no longer used maths at work because 'the computer does it all for me'. It is equally important to take account of the wide range of individual and social strategies for both coping with and developing existing literacy and numeracy skills. These range from relying on colleagues and supervisors for support with form-filling, to taking forms home so that family members can lend assistance.

\footnotetext{
${ }^{1}$ English for speakers of other languages.
} 
Not only did our findings conflict with prevailing policy assumptions about the existence of large-scale literacy and numeracy skills deficiencies in the workplace, they also resonate with those of Livingstone (2009) and are indicative of the capacity of employees to 'make do' with their existing skills and competencies and develop these in response to the exigencies of the workplace, frequently taking advantage of informal learning opportunities of different kinds.

In the case of 'HLN manufacturing' (a large company in the West Midlands), it is noticeable that the vast majority of learners have coped adequately with their existing literacy and numeracy skills. The employees employed numeracy skills (averages, working with diameters) without having formally acquired these skills on a course. Informal learning processes had equipped all the learners (with the exception of one employee who struggled with the metric system) with the necessary skills to undertake their work. The majority of learners engaged on a literacy and numeracy course had developed reasonably advanced level maths through informal learning. Trevor Stephens (a 'Union Learning Representative') described the significance of what he termed 'hands-on learning' in which employees were shown how to use new technology and develop their skills whilst working:

'I think a lot of people though, probably a lot of people on the shop floor, they've been there for years and years, probably are very good mathematically although they haven't done it at school, but by using, through engineering and one thing and another they probably are quite good. We're sort of more advanced maths than sort of basic, sort of equations and working out surface areas and stuff like that but probably having to put it down on paper that's where they could struggle.'

Although employees had to cope with an increasing volume of paperwork as a result of more stringent company surveillance procedures and production quotas, they reported that this was largely of the 'tick box' variety and did not challenge their existing literacy skills. It is noticeable that two of the learners who were interviewed indepth made a point of expressing their appreciation of the course as a means of practising skills which they would otherwise not have the opportunity of developing in their everyday work.

These manifestations of informal learning most frequently took the following forms (see Taylor and Evans, 2009):

- Observing 'Knowledgeables';

- Practising without Supervision;

- Searching Independently for Information;

- Focused Workplace Discussions;

- Mentoring and Coaching.

Informal learning that results from 'Mentoring or Coaching' as well as participating in 'Focused Workplace Discussions' or committees is a complex process that involves 
the interplay of employee agency, workplace relationships and interdependencies and the affordances (the features that invite and enable people to engage) in the wider environment. These variables in some cases promote rich informal learning, for example where 'doors are opened' to opportunities to expand and share knowledge and skills in supportive workgroups. In other cases, workplace discussions and mentoring/coaching can have unintended negative influences on learning, for example where the interdependencies of the workplace are undermined by feelings of lack of trust. The interdependencies inherent in workplace practices are crucial for workplace planning and employee-driven innovation (Billett, 2006). International collaborations with parallel Canadian research (Taylor and Evans, 2009) have expanded existing frameworks for understanding informal learning at work. International case comparison has elicited common themes of relevance to employee engagement in workplace change and innovation, showing the importance of:

- Triggers such as a company ethos of quality performance or safety; safety concerns;

- Attitudes of curiosity, creativity, imagination;

- Inner recognition of personal and work benefits.

On the whole, and in contrast to participation in formal programmes, participation in informal learning was not motivated by the prospect of monetary rewards or upward mobility but 'spurred on by a need for the challenge or a variety in the everyday work routine'.

\section{Interweaving of formal and informal learning in the workplace: creating environments for employee involvement in workplace learning and innovation}

Results of this study have provided evidence on the nature and scope of formal and informal training activities for workers at the lower end of the earnings distribution (see Evans and Waite, 2008; Wolf and Evans (2011). The findings also begin to trace the learning paths of such workers in small, medium and large companies. They show how participating in the more formal workplace programmes, courses and workshops can ignite the desire to do things differently back on the shop floor. In this respect they provide insights into workplace programmes as catalysts of employee involvement in varying work practices and in innovation.

A food processing company from the north of England, 'Coopers', provides for a range of formalized learning within the company structure but also accords official space for opportunities for informal learning including the observation of other employees, and the sharing of ideas in 'huddles'. The increasing 'textualisation' of the Coopers work environment has made employees who struggle with poor literacy and numeracy more prone to miss out on formal training opportunities and increases the significance of 'informal' learning for these particular employees. The learning centre represents an important site for the interweaving of formal and informal learning opportunities. It is noticeable that the popularity of the learning centre rests 
partly on it not being too closely associated with formalized learning. The tutors' loan of laptops and accordance of space for informal self-directed learning on computers ('searching independently for information') has been an important component of the learning centre.

The levelling out of management structures within another case, a Weapons Defence Establishment, has increased the significance of both formal and informal learning opportunities. As part of taking on more responsibility, employees are encouraged to commit themselves to training opportunities through the appraisal system. Whereas previously salaries were consistent within grades of the organization (and negotiated by the union), in the current system promotion and pay depend on individual performance. In this context, employee involvement in formalized training has the potential to bring benefits in terms of promotion and pay. The 'IT and English' courses at this organization have been a success in so far as they have recruited a large number of learners over the long term. Their popularity indicates the importance of workplace courses being tailored to the priorities of the organization in question. In this case, such courses have responded to major structural changes in the company involving the delegation of responsibility to lowerlevel employees and they have been utilized to address a perceived training imbalance amongst the different strata of employees. The levelling out of management structures also has major implications for informal learning. The expectation that employees should 'take on more' and 'show initiative' means that employees are frequently given greater scope for learning about new duties through 'on the job' experience at work.

In the third example, caretakers at Thorpton Local Authority have acquired jobspecific skills and knowledge through a combination of formal and informal learning. The local authority formally allocates more experienced colleagues to guide recently appointed caretakers, but the mentoring process is largely unstructured and informal. The increasing use of report-writing amongst caretakers has underlined the significance of literacy skills and has highlighted a skills deficiency in this area amongst some employees. One caretaker in the in-depth sample made a point of practising his writing skills independently, but was an exception in this regard. Most caretakers have employed various strategies which involve 'getting by' rather than informal learning. In the specific area of literacy, informal learning has not allowed for major skills gaps to be addressed. Reliance on supervisors to fill in forms, for example, does not provide opportunities for informal 'mentoring and coaching' and therefore leaves unaddressed the underlying skills deficiencies. The courses have helped some employees improve their literacy skills and facilitated progression within the workplace. Yet the most significant outcome, highlighted by learners, the tutor and manager alike, has been an increased confidence on the part of employees which has led to development of further formal learning opportunities (through willingness to embark on further learning) as well as informal learning opportunities (through the taking on of higher level roles that also entail 'hands-on' learning).

One of the key findings of the wider study is that employee participation in a formal programme can act as the catalyst for the various informal training activities that occurred back on the shop floor. In the words of one practitioner 'it was like employees were re-awakened to their own learning capabilities as a result of the programme and this provided a different viewpoint about their own workplace and their jobs'. 
Participating in an organized class or in a tutorial session heightened employee awareness of the importance to learn. This interplay between formal and informal training was synergetic. Care should be taken not to confuse strategies for 'getting by' at work with informal learning. Supervisors taking pre-emptive or 'circumventing' action over tasks involving literacy skills can create a vicious circle of employees' over-reliance on supervisors to fill in forms, for example, thus missing the opportunities for informal 'mentoring and coaching' and reinforcing underlying skills deficiencies instead of helping to solve them.

Greater day-to-day job satisfaction was apparent in many of the UK employees who had participated in formal workplace courses, and had developed a greater awareness of the learning potential in their jobs as well as their own abilities to learn. Longer term follow-up is indicating, though, that without advancement or some kind of external recognition stemming from the employee's engagement with a combination of formal and informal workplace learning, this satisfaction can be eroded over time.

Eraut (2004) identified confidence, challenge and supervisory support as significant factors in workplace learning. These factors have particular salience for employee involvement in innovation, as employees gain the confidence to vary work practices in search of improvements. Workers in this study clearly stated the importance of their newly acquired confidence in seeking out further opportunities to learn after participating in a formal programme. However, the confidence to take on new challenges is dependent on the extent to which workers feel supported, not only by supervisors but also through significant co-worker relationships. As Eraut (2004) points out 'if there is neither a challenge nor sufficient support to encourage a person to seek out or respond to a challenge, then confidence declines and with it the motivation to learn' (p. 269).

Eraut's work has been conducted primarily with professionals in graduate occupations. A wider framework for understanding the organizational context is provided by Evans et al. (2006), who argue on the basis of extended research with employees ranging from basic level workers to graduate apprentices in more than 40 organisations, that interventions need to address both employee and employer interests, recognizing that these often represent different rationalities and follow a different logic about what matters at work. The involvement of employee representatives contributes to the expression of employees' interests and can reassure them that gains in productivity will not have a negative impact on jobs and conditions of employment, where this is genuinely the case (Rainbird et al., 2004). While learning needs to be seen as an integral part of practice, attention needs to be paid to the environment as a whole, for example, the work environment, as well as formal learning, affects how far formal learning can be a positive trigger for further learning. A short-term timeframe and a narrow of view of learning, dominated by measurable changes in performance, will not enhance the learning environment and can stifle innovation.

A 'social ecology' (Evans et al., 2009) of learning in the field of adult basic skills leads us to consider the relationships between the affordances of the workplace (or those features of the workplace environment that invite us to engage and learn), the 
types of knowledge afforded by 'essential skills' learning (including knowing how and 'knowing that you can') and the agency or intention to act of the individual employee, reflected in their diverse motivations.

These are triangular relationships and mutually interdependent sets of interactions. There are affordances for learning in all workplace environments. Some are more accessible and visible than others. The intention of employees to act in particular ways in pursuit of their goals and interests, whether in their jobs or personal lives, makes the affordances for learning more visible to them. The know-how associated with work practices such as report-writing or finding better ways of expressing oneself, and the confidence of 'knowing that you can' often develop as the person engages with the opportunity. The process of making the affordances for learning more visible can itself generate some employees' will to act on and use those affordances, and new knowledge and ways of working. In the shifting attitudes to learning, the changing levels of know-how and the confidence that comes from 'knowing that you can' both stimulate action and create conditions for employee involvement in innovation. In the UK, the evidence to date suggests considerable diversity of motivations reflective of the complexities of the workplace context, variations in the quality of working environments and the differential positions of employees within workplace hierarchies. From a qualitative point of view this study of basic level employees provides some partial insights into these questions. More fundamentally, reflexive and interdependent understandings are needed of how conditions are created for employee involvement in workplace learning and innovation. This has to encompass the relationships among employees, context and opportunities. For example, informal learning can also result from coaching as well participating in focused workplace discussions or committees. This type of workrelated learning is a complex process that involves the interplay of employee agency, workplace relationships and interdependencies and the affordances of the wider environment. These variables, in some instances, promote rich informal learning, where 'doors are opened' to opportunities to expand and share knowledge and skills in supportive workgroups. In other cases, workplace discussions and the mentoring of another worker can have unintended negative influences on learning, for example where the interdependencies of the workplace are undermined by feelings of lack of trust. Sociocultural understandings of ways in which knowledge and learning are constructed through social interactions in and beyond the workplace lead to reconceptualisations (see Evans and Niemeyer, 2004; Billett, 2006; Evans, et al 2006; Evans, 2009) that can embrace the interdependencies inherent in varying or changing workplace practices in the cause of innovation.

\section{Conclusion}

There is a major disjunction between policy assumptions about large-scale literacy and numeracy deficiencies in the UK and employees' capacity to cope with their existing skills and competencies. This disjunction has emerged as a result of the adoption of a narrowly defined skills agenda and vague assumptions about the needs of a post-industrial, 'knowledge economy'. 
The adoption of a 'deficiency model' fails to take account of individuals' capacity to use their existing skills and competencies and tailor them to the actual demands of the workplace. Furthermore, positioning adults as deficient in skills does not provide appropriate encouragement to them to expand their capacities in ways that can benefit their workplaces, although many do take opportunities to learn in a variety of ways that are important to them and their families, both in and outside work. Generating an interplay between formal and informal learning can help to create the environments for employees in lower grade jobs to use and expand their skills in and through the workplace. This workplace learning supports participation in employeedriven innovation, as workers engage with others to vary, and eventually to change, work practices. Companies that aim to expand and enrich job content in jobs at all levels are likely to find employees working to expand their capacities accordingly. However those who send employees on 'basic skills' courses only to return them to a job and work environment that provides no opportunities for their use are likely to see the benefits of their investment eroded over time. To be effective, workplace initiatives designed to support learning and innovation have to be based on realistic evaluations of the contexts and balances of advantage at three levels: the sociopolitical and organisational level (including the regulatory frameworks that govern the wage relationship), the immediate workplace environments, and the employees' dispositions to learn (Evans et al., 2006). When these conditions are met, the interplay between formal and informal learning can be powerful in creating environments and stimuli for employee involvement in innovation. For sustainability, government intervention is best directed in redressing the 'market failures' inherent in companies' investments in workforce development by supplementing companies' and unions' own efforts in these directions rather than importing external courses disconnected from core organisational concerns.

Funding: This work was supported by the Economic and Social Research Council [ESRC Award RES-139-25-0120 and Award RES-594-28-0001].

\section{References}

Ananiadou K, Jenkins A, and Wolf A (2003) The benefits to employers of raising workforce basic skills levels: a review of the literature. London: NRDC.

Barton D (1994) Literacy: An introduction to the ecology of written language. London: Blackwell.

Barton D, Hamilton M (1998) Local Literacies: Reading and Writing in One Community. London: Routledge. 
Billett S (2002) Toward a workplace pedagogy: Guidance, participation and engagement. Adult Education Quarterly 53(1): 27-43.

Billett S (2006) Work, change and workers. Dordrecht, Holland: Springer.

Chisholm L, Fennes H, and Spannring R (eds) (2007) Competence Development as Workplace Learning. Innsbruck: Innsbruck University Press.

Department for Education and Skills (2001) Skills for Life: the national strategy for improving adult literacy and numeracy skills. London: Department of Education and Skills.

Elkjaer B, Hǿyrup S, and Pedersen KL (2007) Contemporary Nordic Research on Workplace Learning. In: Chisholm L, Fennes H, and Spannring R (eds) Competence Development as Workplace Learning. Innsbruck: Innsbruck University Press.

Eraut M (2004) Informal learning in the workplace. Studies in Continuing Education 26(2): 247-273.

Ernst and Young (1993) Literacy, Education and Training: Their Impact on the UK Economy. London: Ernst and Young.

Evans, K (2006) Achieving equity through gender autonomy: the challenges for vocational education and training policy and practice, Journal of Vocational Education and Training, 58 (4) 393 - 409

Evans K (2009) Learning. Work and Social Responsibility: Challenges for Lifelong Learning in a Global Age. Dordrecht: Springer

Evans K, Niemeyer B (2004) Reconnection: Countering Social Exclusion Through Situated Learning. Dordrecht: Springer.

Evans K, Waite E (2009) Adults Learning in and through the workplace. In: Ecclestone K, Biesta G, and Hughes M (eds) Change and Becoming through the Lifecourse: Transitions and Learning in Education and Life. Abingdon: Routledge. 162-181.

Evans K, Waite E (2008) Adult Workers' Engagement in Formal and Informal Learning: Insights into Workplace Basic Skills from Four UK Organisations. National Adult Literacy Database (Canada) Fredericton, New Brunswick : NALD.. 
Evans K, Waite E, and Admasachew L (2009) Enhancing Skills for Life?: Workplace learning and adult basic skills. In: Reder S, Bynner J Tracking adult basic skills: findings from longitudinal research. London and New York: Routledge. 242-260

Evans K, Waite E, and Kersh N (2010) Towards a social ecology of adult learning in and through the workplace. The Sage Handbook on Workplace Learning, London: Sage.

Evans K, Hodkinson P, Rainbird H, and Unwin L (2006) Improving Workplace Learning. London: Routledge.

Fairclough N (2003) Analysing Discourse: Textual Analysis for Social Research. London: Routledge.

Felstead A, Gallie D, Green F, and Zhou Y (2007) Skills at Work 1986-2006. Oxford: University of Oxford, SKOPE.

Fuller A, Unwin L (2003) Learning as Apprentices in the Contemporary UK Workplace: creating and managing expansive and restrictive participation. Journal of Education and Work 16(4): 407-426.

Gee JP (1996) Social Linguistics and Literacies. London: Taylor and Francis.

Green F (2009) Employee Involvement, Technology, Job Tasks and Required Education ESRC LLAKES Seminar, 15 June, Institute of Education, University of London.

Leitch Review of Skills (2006) Prosperity for all in the global economy - world class skills. Final Report. London: H M Treasury.

Livingstone, D (2001) Adults' informal learning: Definitions, findings, gaps and future research. NALL Working Paper 21-2001. Centre for the Study of Education and Work, Ontario Institute for the Study of Education, University of Toronto.

Available at:

http://www.oise.utoronto.ca/depts/sese/csew/nall/res/21adultsifnormallearning.ht $\underline{\mathrm{m}}$ 
Livingstone, D (2009) We Don't Need No Education. Education Alliance Quarterly May Issue: 23-25.

Mayhew K, Keep E (1999) The Assessment: Knowledge, Skills and Competitiveness. Oxford Review of Economic Policy 15(1): 1-15.

OECD (1997) Literacy Skills for the Knowledge Society. Paris: OECD.

Papen U (2005) Adult Literacy as Social Practice: More than Skills. London: Routledge.

Rainbird H, Fuller A, Munro, A (2004) Workplace Learning in Context Abingdon: Routledge

Sargant (2000) The Learning Divide Revisited: Report on the Findings of UK-wide Survey of Adult Participation. Leicester: NIACE.

Street BV (1993) Introduction: the new literacy studies. In: Street BV (ed.) CrossCultural Approaches to Literacy. Cambridge: CUP. 1-22

Taylor M, Evans K (2009) Formal and Informal Training for Workers with Low Literacy: Building an International Dialogue between Canada and the United Kingdom. Journal of Adult and Continuing Education, 15(1): 37-54.

Taylor M, Evans K, and Abasi A (2007) Understanding teaching and learning in adult literacy training: Practices in Canada and the United Kingdom. Literacy and Numeracy Studies: An International Journal in the Education and Training of Adults 15(2): 57-72.

Thompson P (2004) Skating on Thin Ice - the knowledge economy myth. Glasgow: Big Thinking.

Williams J (2003) The Skills for Life survey: a national needs and impact survey of literacy, numeracy and ICT skills. London: TSO.

Wolf A, Waite $E$ (2007) Reaching the learners that other provision does not reach. Reflect 9. London: NRDC, 10-11. 
Wolf A, Evans K 2009 End of Award Report: Enhancing Skills for Life? Swindon: Economic and Social Research Council.

Wolf A, Evans K, with Aspin L, Waite E (2010 in press) Improving Literacy at Work. Abingdon: Routledge.

Wolf A, Aspin L, Waite E, and Ananiadou K (2010 in press) 'And leave not a wrack behind': lessons from the rise and fall of workplace basic skills programmes. Oxford Review of Education. Scheduled for Vol. 36 No. 4.

\footnotetext{
i See OECD (1997) for a description of the IALS survey. More recently, the Skills for Life needs survey of 2002/3, produced a lower indication of those adults who struggle with literacy, with an estimate of 5.8 million people below Level 1 (Williams, 2003).

ii The research, supported by major awards from the Economic and Social Research Council and by the National Research and Development Centre (NRDC), involves ongoing longitudinal exploration of the impact on both learners and their organisations of government-funded and other workplace programmes designed to increase the literacy skills of employees. From 2003-2008 research was conducted as part of the TLRP Research Programme. From 2008 further research is in progress through an award to establish the ESRC LLAKES Centre for Learning and Life Chances in Knowledge Economies and Societies. ESRC Award RES-139-25-0120 Adult Basic Skills and Workplace Learning; Award RES-594-28-0001 LLAKES (Learning and Life Chances in Knowledge Economies and Societies) Centre, Project 3.2.

iii The Go! Reading tests have two overlapping question papers; Readers were allocated tests on the basis of tutors' own pre-testing. In the event that this had not occurred, a short screening test was used.)
} 